Mediscope

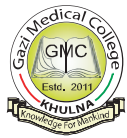

The Journal of GMC

\title{
Maternal iodine status reflects the iodine status of their breast-fed infants
}

\author{
GM Molla ${ }^{1}$, FH Mollah², MT Milky ${ }^{3}$, DK Sunyal ${ }^{4}$, MI Arslan ${ }^{5}$
}

\begin{abstract}
The objective of the observational analytical study was to assess the iodine status of lactating mothers and their breast-fed infants and to evaluate whether maternal iodine status reflects the iodine status of their breast-fed infants. The study was carried out in the department of Biochemistry, Bangabandhu Sheikh Mujib Medical University, Dhaka with active cooperation of Kumudini Women's Medical College Hospital, Mirzapur, Tangail involving fifty lactating mothers and their exclusively breast-fed infants. Early morning urine and breast milk samples were collected in dry and clean plastic container free from any chemical contamination. Urinary iodine excretion (UIE) was used as indicator for assessing iodine status. The median (range) urinary iodine concentration of lactating mothers and their breast-fed infants were $225.3 \mu \mathrm{g} / \mathrm{L}$ (61.5-530.0) and $225.8 \mu \mathrm{g} / \mathrm{L}$ (100.5-526.0), respectively. Of the mothers, $96 \%$ (48) had no biochemical iodine deficiency (UIE $\geq 100 \mu \mathrm{g} / \mathrm{L}$ ), only $4 \%$ (2) had mild biochemical iodine deficiency (UIE, 50-99 $\mathrm{g} / \mathrm{L}$ ). There was no biochemical iodine deficiency of breast-fed infants. The median breast-milk iodine concentration was $157 \mu \mathrm{g} / \mathrm{L}$ which was more than three times of recommended minimum concentration $(50 \mu \mathrm{g} / \mathrm{L})$. lodine in breast milk of lactating mothers was positively correlated with their UIE $(p<0.01)$. Infant's urinary iodine was positively correlated with iodine concentration in breast milk $(p<0.01)$ and also positively correlated with urinary iodine of lactating mothers $(p<0.01)$. Lactating mothers and their breast-fed infants in this study were iodine sufficient. lodine status of exclusively breast-fed infants can be determined by the iodine status of their mothers.
\end{abstract}

Key words: Urinary iodine excretion, breast milk iodine concentration, iodine status, lactating mothers, exclusively breast-fed infants.

\section{Introduction}

Human Infants are sensitive to maternal iodine nutrition during fetal development and later during Breast feeding. ${ }^{1}$ lodine deficiency during post-partum period has the potential to affect neonatal neuropsycho intellectual development. ${ }^{2}$ Breast milk is the only source of iodine for the exclusively

1. GM Molla, MBBs, MPhill, Professor, Dept. of Biochemistry, Gazi Medical College, Khulna. Email: golammorshed56@yahoo.com

2. FH Mollah, MBBS, MPhill, Associate Professor, Dept. of Biochemistry, BSMMU, Dhaka, Bangladesh

3. MT Milky, Consultant, Dept. of Gynae \& Obs., Verk Mother \& Children Hospital, Savar, Dhaka

4. DK Sunyal, MBBS, MPhill, Professor, Dept. of Physiology, Gazi Medical College, Khulna

5. MI Arslan, Professor, Dept. of Biochemistry, BSMMU, Dhaka, Bangladesh 
breast-fed neonates and infants. Bangladesh is an iodine deficient region ${ }^{3}$ and the government of Bangladesh, with assistance of UNICEF had initiated a universal salt iodinization to provide iodized salt by the middle of 1994. Excessive iodine intake also causes hyperthyroidism, iodine induced hypothyroidism, autoimmune thyroid diseases. ${ }^{4-6}$ Despite the importance of iodine for infants' health, there have been limited studies addressing iodine status of lactating mothers and their breast-fed infants, whether maternal iodine status reflects the iodine status of their breast-fed infants. Routine measurement of breast milk iodine concentration is very difficult in our country due to some social and religious barrier. So it is necessary to propose a method on how to predict the iodine content in breast milk. For these reasons, this study was designed and urinary iodine excretion (UIE) was used as the indicator for assessing iodine status.

\section{Materials and Method}

This observational analytical study was carried out in the department of Biochemistry, Bangabandhu Sheikh Mujib Medical University (BSMMU), Dhaka with active cooperation of Kumudini Women's Medical College Hospital, Mirzapur, Tangail. Fifty lactating mothers and their exclusively breast- fed infants were included in this study. The age of the lactating mothers and their breast-fed infants were 20-40 years and 3-180 days and they had no known endocrine, renal, cardiovascular and liver diseases. All the subjects were informed in details about the nature and purpose of study and included in the study only when they had given their written consent. Early morning urine and breast milk samples were collected in dry and clean plastic container free from any chemical contamination. Temporarily these were kept in an ice box for preservation just after collection and during transportation and finally these were preserved in $\mathrm{a}-35^{\circ} \mathrm{C}$ freezer till the test was performed. Urinary iodine of lactating mothers and their breast-fed infants and breast-milk iodine were estimated by spectrophotometer based on the principle of Sandell-Clothoff reaction. ${ }^{7-9}$ All statistical analyses ware done by using SPSS (Statistical Programme for Social Science) $12^{\text {th }}$ version software package for windows. Urinary iodine and breast milk iodine level do not follow the normal distribution. Thus Spearman's correlation coefficient test (' $r$ ' test) was done to see the correlation. The significance test was done at $95 \%$ confidence level.

\section{Results}

The mean age \pm SD (range) of lactating mothers was $24.9 \pm 4.4(20-36)$ years and their breast-fed infants were $78.2 \pm 59.1$ (5-180) days. The median (range) urinary iodine concentration of lactating mothers and their breast-fed infants were $225.3 \mu \mathrm{g} / \mathrm{L}$ (61.5-530.0) and $225.8 \mu \mathrm{g} / \mathrm{L}$ (100.5-526.5), respectively. The median (range) breast-milk iodine concentration was $157 \mu \mathrm{g} / \mathrm{L}$ (54.5-431.5) (Table 1). Out of 50 lactating mothers, 48 (96\%) mothers had no biochemical iodine deficiency (UIE $\geq 100 \mu \mathrm{g} / \mathrm{L}$ ), only $2(4 \%)$ had mild biochemical iodine deficiency (UIE, 50-99 $\mu \mathrm{g} / \mathrm{L}$ ) (Table 2). There was no biochemical deficiency of breast-fed infants (UIE $\geq 100 \mu \mathrm{g} / \mathrm{L}$ ) (Table 3). lodine in breast-milk of lactating mothers was positively correlated with their urinary iodine excretion ( $p$ $<0.01$ ) (Figure 1). Infant's urinary iodine was positively correlated with iodine concentration in breast milk $(p<0.01)$ and also positively correlated with urinary iodine of lactating mothers $(p<0.01)$ (Figure 2, Figure 3). Out of 50 breast-fed infants, $37(74 \%)$ infants were taken breast-fed 10-12 times, 11 (22\%) infants were taken more than 12 times and 2 (4\%) were taken less than 10 times in 24 hours.

\section{Discussion}

This study was aimed to asses the iodine status of lactating mothers and their exclusively breast- fed infants, to evaluate whether maternal iodine status reflects the iodine status of their exclusively breast-fed infants and how to predict the iodine content of breast milk. Urinary iodine, breast milk iodine of fifty lactating mothers and urinary iodine of their breast-fed infants were 
Table 1. Median and range of breast milk iodine, urinary iodine of lactating mother and urinary iodine of their breast-fed infants

\begin{tabular}{lcc}
\hline Parameter & Median & Range \\
\hline $\begin{array}{l}\text { Breast milk iodine } \\
\text { concentration }(\mu \mathrm{g} / \mathrm{L}) \\
(\mathrm{N}=50)\end{array}$ & 157.0 & $54.0-431.5$ \\
$\begin{array}{l}\text { Mothers urinary iodine } \\
\text { concentration }(\mu \mathrm{g} / \mathrm{L}) \\
(\mathrm{N}=50)\end{array}$ & 225.3 & $61.5-530.0$ \\
$\begin{array}{l}\text { Infants urinary iodine } \\
\text { concentration }(\mu \mathrm{g} / \mathrm{L})\end{array}$ & & \\
$(\mathrm{N}=50)$ & 225.8 & $100.5-526.5$ \\
& & \\
& $\mathrm{n}=$ Number of Subjects
\end{tabular}

Table 2. lodine status of lactating mothers using urinary iodine as the indicator

\begin{tabular}{lcc}
\hline lodine status & Number $(\mathbf{n}=\mathbf{5 0})$ & $\%$ \\
\hline $\begin{array}{l}\text { Moderate to severe of deficiency } \\
\text { (Median Urinary iodine }<50 \mu \mathrm{g} / \mathrm{L})\end{array}$ & 0 & 0 \\
$\begin{array}{l}\text { Mild deficiency } \\
\text { (Median Urinary iodine } 50-99 \mu \mathrm{g} / \mathrm{L})\end{array}$ & 2 & 4 \\
$\begin{array}{l}\text { Normal } \\
\text { (Median Urinary iodine }>100 \mu \mathrm{g} / \mathrm{L})\end{array}$ & 48 & 96 \\
\hline
\end{tabular}

$\mathrm{n}=$ Number of Subjects

Table 3. lodine status of brest-fed infants using urinary iodine as the indicator

\begin{tabular}{lcc}
\hline lodine status & Number $(\mathbf{n}=\mathbf{5 0})$ & $\%$ \\
\hline $\begin{array}{l}\text { Deficiency } \\
\text { (Median Urinary iodine }<100 \mu \mathrm{g} / \mathrm{L})\end{array}$ & 0 & 0 \\
$\begin{array}{l}\text { Normal } \\
\text { (Median Urinary iodine }>100 \mu \mathrm{g} / \mathrm{L})\end{array}$ & 50 & 100 \\
\hline
\end{tabular}

$\mathrm{N}=$ Number of Subject

measured. Median urinary iodine concentration of lactating mothers was 225.3 $\mu \mathrm{g} / \mathrm{L}$ which was within normal range. Out of fifty lactating mothers, 48 (96\%) mothers had no biochemical iodine deficiency. Only 2 (4\%) mothers had mild biochemical iodine deficiency. According to the WHO lactating mothers of this study were iodine sufficient. ${ }^{6}$ The median urinary iodine concentration of breast-fed infants was $225.8 \mu \mathrm{g} / \mathrm{L}$ which was normal. It indicates there was no biochemical iodine deficiency of breast-fed infants and they get sufficient iodine from their mother's milk. The median breast milk concentration was $157 \mu \mathrm{g} / \mathrm{L}$ which was within optimum range, ${ }^{8}$ but more than three times of recommended minimum concentration. ${ }^{10}$ It was observed that two mothers had mild 


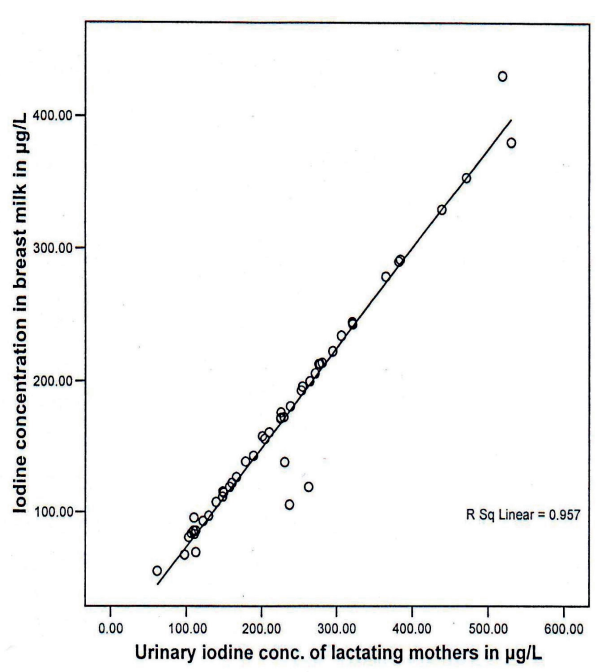

Figure 1: Correlation between urinary iodine and breast milk iodine of lactating mothers.

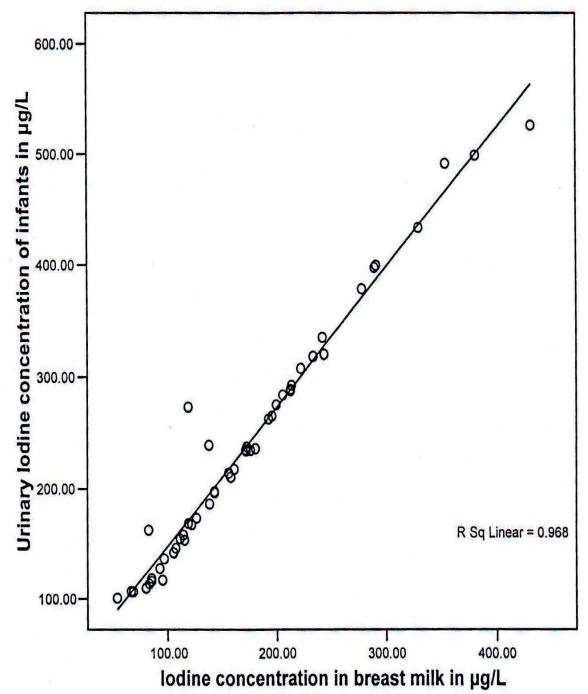

Figure 2: Correlation between infant's urinary iodine and breast milk iodine.

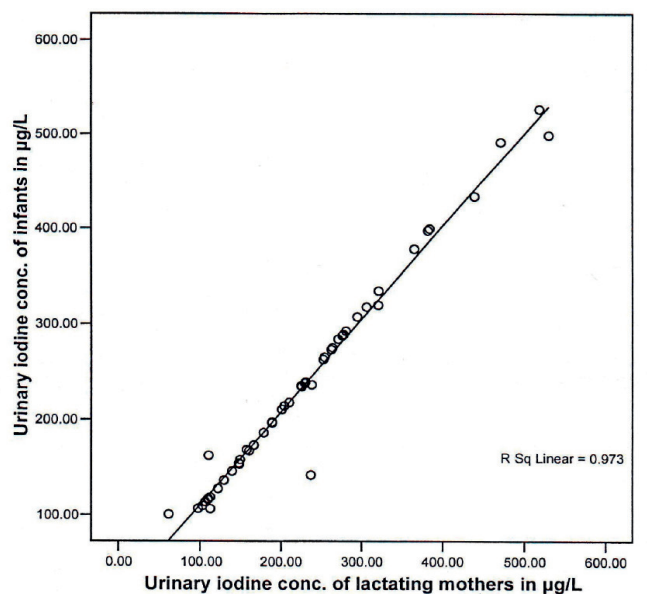

Figure3: Correlation between urinary iodine of lactating mothers and their breast-fed infants. biochemical iodine deficiency but iodine concentration in breast milk of all lactating mothers was above the recommended minimum concentration. It may be due to mammary glands have ability to uptake iodine against electrochemical gradient. ${ }^{11}$ In this study, breast milk iodine concentration was positively correlated with UIE of lactating mothers $(p<0.01)$. It indicates UIE of lactating mothers predict the iodine content of their breast milk. This finding was consistent with the observation reported by others. ${ }^{8,12}$ It was also observed that, the lowest value of measured urinary iodine concentration of lactating mothers was 61.5 $\mu \mathrm{g} / \mathrm{L}$ and their corresponding breast milk iodine concentration was $54.5 \mu \mathrm{g} / \mathrm{L}$ which was below the optimum concentration but just above the recommended minimum concentration. It indicates lactating mothers of moderate to severe iodine deficiency is a risk for their breast milk contain low iodine concentration. This observation was supported by the observation of Pong paew et al. ${ }^{8}$ In this study, infants urinary iodine concentration was positively correlated with iodine concentration in breast milk $(p<0.01)$ and also positively correlated with maternal urinary iodine concentration. It indicates that maternal iodine status reflects the iodine status of their breast-fed infants. Out of the 50 breast-fed infants, 37 (74\%) infants were taken breast-fed 10-12 times, 11 (22\%) infants were taken more than 12 times, and only $2(4 \%)$ infants were taken less than 10 times in 24 hours. So, apparently it is said that if breast milk iodine concentration is within normal range, 10-12 numbers of feeding in 24 hours for infants is enough to get sufficient iodine from their mothers milk.

\section{Conclusion}

Lactating mothers and their breast-fed infants of this study were iodine sufficient. Iodine status of exclusively breast-fed infants can be determined by the iodine status of their mothers. Urinary iodine excretion of lactating mothers predicts the iodine content of their breast-milk. If iodine content of breast-milk is within normal range, 10-12 numbers of feeding in 24 hours for infants is enough to get sufficient iodine from their mother's milk. 


\section{References}

1. Dorea JG. lodine nutrition and breast feeding. J Trace Elem Med Biol 2002;16(4):207-20.

2. Chan SS, Hams G, Wiley V, Wilcken B, McElduff A. Postpartum maternal iodine status and the relationship to neonatal thyroid function. Thyroid 2003; 13(9):873-76.

3. Yousuf HK, Quaz IS, Khan MR, et al. lodine deficiency disorders in Bangladesh. Indian J Pediatr 1997;63(1): 105-10.

4. Nishiyama S, Mikeda T, Okada T, Nakamura K, Kotani T, Hishinuma A. Transient hypothyroidism or persistent hyper thyrotropinemia in neonates born to mothers with excessive iodine intake. Thyroid 2004;14(12):1043-77.

5. Luberg P, Perderson B, Knudsen N, Ovesen L, Anderson S. Environmental iodine intake affects the type of non malignant thyroid diseases. Thyroid. 2001;11(5): 457.

6. World Health Organization (WHO). Assessment of iodine deficiency disorders and monitoring their elimination. A guide for programme managers. $2^{\text {nd }}$ ed., Geneva: WHO, 2001.

7. Dunn JT, Crutchfield HE, Gutekunst R, Dun D. Method for measuring iodine in urine. Netherlands: ICCIDD,1993.

8. Paew PP, Supawan V, Tungtrongchir R, et al. Urinary iodine excretion as a predictor of the iodine content of breast milk. J Med Assoc Thai 1999; 82(3): 284-9.

9. World Health Organization (WHO). Progress to ward the elimination of iodine deficiency disorders (IDDs). Geneva: WHO; 1999, pp.1-33.

10. Seibold- Weiger K, Wollmann H, Rendi J, Ranke M, Sper C. lodine concentration in the breast milk of mothers of prematureinfants. Geburtshilfe Neonatol 2003; 203(2):81-85.

11. Granner DK. Thyroid hormones. In: Murray RK, Granner DK, Mayes PA, Rodwell VW. editors. Harper's Biochemistry. 25 ${ }^{\text {th }}$ ed. London: Hall international (UK) Limited; 2000, pp.561-6.

12. Nelson M, Phillips DI, Morris JA, Wood T. Urinary iodine excretion correlates with milk iodine content in seven British town. $\mathrm{J}$ Epidemiol Community Health 1998; 42(1):72-5.

\section{Suggestion for citation of the above:}

Molla GM, Mollah FH, Milky MT, Sunyal DK, Arslan MI. Maternal iodine status reflects the iodine status of their breast-fed infants. Mediscope 2015;2(1):13-7. 